\title{
Inhibitory effects of the cyclooxygenase- 2 inhibitor, etodolac, on colitis-associated tumorigenesis in p53-deficient mice treated with dextran sulfate sodium
}

\author{
KENICHIROH MUKAWA ${ }^{1,2}$, SHIGEHIKO FUJII ${ }^{1,3}$, KEIICHI TOMINAGA ${ }^{1,2}$, NAOTO YOSHITAKE $^{1,2}$, \\ AKIHITO ABE ${ }^{1}$, TOKUYUKI KONO ${ }^{1}$, AKIRA SEKIKAWA ${ }^{1}$, HIROKAZU FUKUI ${ }^{1}$, \\ KAZUHITO ICHIKAWA ${ }^{1}$, SHIGEKI TOMITA ${ }^{1}$, JOHJI IMURA ${ }^{1}$, YUKO ONO ${ }^{1}$, \\ MOTOO SHINODA $^{4}$, HIDEYUKI HIRAISHI ${ }^{2}$ and TAKAHIRO FUJIMORI ${ }^{1}$ \\ Departments of ${ }^{1}$ Surgical and Molecular Pathology and ${ }^{2}$ Gastroenterology, Dokkyo Medical University School \\ of Medicine, Tochigi; ${ }^{3}$ Department of Gastroenterology and Hepatology, Kyoto University Graduate School \\ of Medicine, Kyoto; ${ }^{4}$ Laboratory Animal Research Center, Dokkyo Medical University, Tochigi, Japan
}

Received August 27, 2007; Accepted October 11, 2007

\begin{abstract}
Non-steroidal anti-inflammatory drugs (NSAIDs) and cyclooxygenase-2 (COX-2) inhibitors are representative agents for the chemoprevention of sporadic colorectal neoplasia. However, few reports have described the chemopreventive effects of such agents on colitis-associated tumorigenesis. To clarify whether treatment with the COX-2 inhibitor may reduce the risk of colitis-associated neoplasia, we investigated the effect of one such agent, etodolac, on tumorigenesis in the colitis-associated neoplasia model using p53-deficient mice treated with dextran sulfate sodium (DSS). The $\mathrm{p} 53^{-/}$mice were divided into four groups: i) treatment with DSS + etodolac, then after two cycles of DSS, the mice were given distilled water for 84 days. In addition, etodolac was administered three times a week at a dose of $10 \mathrm{mg} / \mathrm{kg}$ body weight throughout the experiment. ii) Treatment with two cycles of DSS only, followed by distilled water for 84 days. iii) Treatment with etodolac alone. iv) Distilled water alone was administered to the control group. The incidence of mice with neoplasia was $82.4 \%$ in the DSS + etodolac group and
\end{abstract}

Correspondence to: Dr Shigehiko Fujii, Department of Surgical and Molecular Pathology, Dokkyo Medical University School of Medicine, 880 Kitakobayashi, Mibu, Shimotsuga, Tochigi 321-0293, Japan

E-mail: s-fujii@dokkyomed.ac.jp

Abbreviations: UC, ulcerative colitis; NSAIDs, non-steroidal antiinflammatory drugs; COX-2, cyclooxygenase-2; DSS, dextran sulfate sodium; AOM, azoxymethane; DMH, 1,2-dimethylhydrazine; IBD, inflammatory bowel disease; TNB, trinitrobenzene sulfonic acid

Key words: colitis-associated tumorigenesis, cyclooxygenase-2 inhibitor, chemoprevention
$100 \%$ in the DSS-alone group. No neoplasia was observed in the etodolac-alone and control groups. The mean $( \pm$ SEM) number of total neoplasias per mouse was $1.29 \pm 0.2$ in the DSS + etodolac group and 3.0 \pm 0.52 in the DSS-alone group, the inter-group difference being significant $(\mathrm{p}<0.01)$. There was no significant difference in the inflammation score between these two groups. These results showed that treatment with etodolac significantly reduced the occurrence of neoplasia, suggesting that this COX-2 inhibitor has chemopreventive activity against colitis-associated tumorigenesis.

\section{Introduction}

Patients with ulcerative colitis (UC) show an increased incidence of colorectal neoplasia and UC-associated colorectal neoplasia represents a major cause of increased mortality in such patients (1). In order to improve the prognosis of patients with UC-associated neoplasia, diagnosis at an early or precancerous stage is crucial. A predisposition to colorectal neoplasia in patients with UC is generally considered to depend on two risk factors: the presence of long-standing disease and extensive colitis $(2,3)$. Therefore, surveillance colonoscopy with multi-step biopsy has been widely recommended for patients with long-standing and/or extensive UC (4-6). However, studies on the efficacy of surveillance in UC have produced conflicting results and have suggested that surveillance allows for the detection of early-stage neoplasia in only a minority of patients and cannot guarantee cancer detection at a curable stage (7-10).

Non-steroidal anti-inflammatory drugs (NSAIDs) and cyclooxygenase-2 (COX-2) inhibitors are representative agents for the chemoprevention of sporadic colorectal neoplasia. Numerous experimental and clinical studies have indicated that such agents significantly inhibit tumorigenesis in humans with sporadic colorectal neoplasia and in the rodent model of colorectal tumorigenesis (11-14). However, few reports have described the chemopreventive effect of 


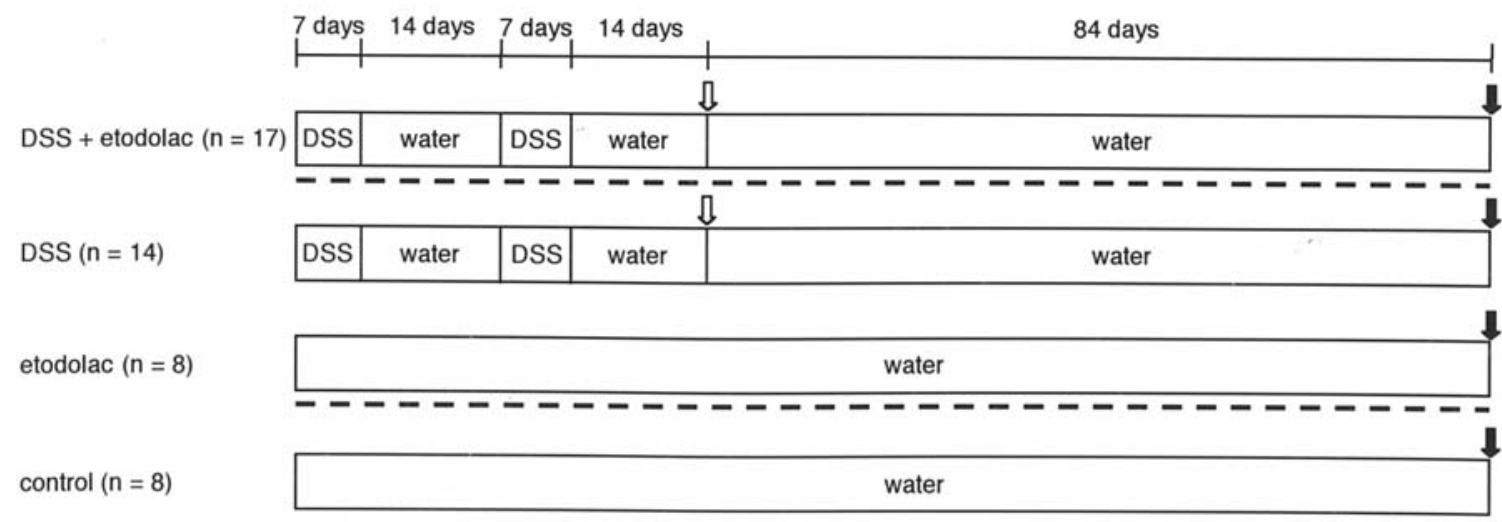

Figure 1. Experimental design. Broken line, oral administration of etodolac (10 mg/kg), 3 times/week; black arrows, sacrifice at 126 days; white arrows, sacrifice at 42 days.

NSAIDs and COX-2 inhibitors on colitis-associated tumorigenesis (15-18). Therefore, it is still unclear whether treatment with these agents provides as much protection against colorectal neoplasia in patients with $\mathrm{UC}$ as in patients without UC.

We recently developed a new model of colitis-associated neoplasia in p53-deficient mice by treatment with dextran sulfate sodium (DSS) and found that the macroscopic morphology and genetic alterations in the resulting neoplasia are similar to those of human UC-associated neoplasia (19). In the present study, to clarify whether treatment with the COX-2 inhibitor may reduce the risk of colitis-associated neoplasia, we investigated the effect of one such agent, etodolac, on tumorigenesis in the colitis-associated neoplasia model using p53-deficient mice.

\section{Materials and methods}

Animals. Specific pathogen-free mice with a homozygous p53 deficiency (p53/- mice) were used for the study. The p53 $\%$ mice with a C57BL/6 and CBA background were produced by Tsukada and colleagues (20) and kindly provided by Dr Norio Ishida (Clock Cell Biology Group, Institute for Biological Resources and Functions, National Institute of Advanced Industrial Science and Technology, Tsukuba, Japan).

Experimental procedure. Fig. 1 shows the experimental design. All of the mice were eight weeks old at the beginning of the experiment. The colitis was induced by feeding 3\% DSS (ICN Biomedicals Inc., Aorano, OH, USA), molecular weight 36,000-50,000, dissolved in drinking water which was given ad libitum. One cycle was defined as seven days of DSS followed by 14 days of distilled water. The COX-2 inhibitor, etodolac (kindly provided by Nippon Shinyaku Co., Ltd., Kyoto, Japan), was suspended in $0.5 \%$ methylcellulose (ShinEtsu Chemical Co., Ltd., Tokyo, Japan) to give a concentration of $1 \mathrm{mg} / \mathrm{ml}$. The mice were divided into the following 4 groups: i) treatment with DSS + etodolac, then after two cycles of DSS, the mice were given distilled water for 84 days. In addition, etodolac was administered three times a week by oral gavage at a dose of $10 \mathrm{mg} / \mathrm{kg}$ body weight throughout the experimental period. ii) Treatment with two cycles of DSS only, followed by distilled water for 84 days. In addition, distilled water was administered three times a week by oral gavage in a comparable volume $(10 \mathrm{ml} / \mathrm{kg}$ body weight $)$ throughout the experiment. iii) Treatment with etodolacalone in the same manner as that in the DSS + etodolac group. iv) Distilled water alone was administered to the control group, in the same manner as that in the DSS-alone group. To evaluate the incidence of neoplasia and the severity of chronic colitis in the late phase, the mice in the four groups were sacrificed by cervical dislocation at 126 days. In addition, to evaluate the severity of acute colitis in the early phase, six mice in the DSS + etodolac group and five in the DSS-alone group were sacrificed at 42 days.

The colons of the mice were removed, cut open along the longitudinal median axis, rinsed with saline and fixed in neutral aqueous phosphate-buffered $4 \%$ formaldehyde for $8 \mathrm{~h}$. Then the entire colon was stained with alcian blue $(\mathrm{pH} 2.5)$ and the surface microstructure was observed using a stereomicroscope (Olympus, Tokyo, Japan) and examined for the presence of neoplasia. All gross lesions suspected to be neoplasia were sectioned under stereomicroscopic observation. The remaining tissues were sectioned at intervals of $3 \mathrm{~mm}$, embedded in paraffin and stained with hematoxylin and eosin. The whole extracted colon was divided equally into three portions starting from the proximal colon, followed by the middle and distal colon.

This experiment was carried out under the control of the Animal Care and Use Committee, Dokkyo Medical University, in accordance with the University Guidelines for the Care and Use of Laboratory Animals.

Histological assessment of neoplasia. Macroscopically, neoplasias were classified into two types: superficial and protruding. The superficial type was defined as a lesion with a height not greater than twice the thickness of the adjacent non-neoplastic epithelium. The protruding type was defined as a lesion that clearly projected above the surface of the adjacent non-neoplastic epithelium.

Histologically, each sample was examined by three experienced pathologists in a blinded manner and neoplasias were classified according to the Vienna classification of 
Table I. Body and liver weights and colon length in each group.

\begin{tabular}{lcccc}
\hline Group & $\mathrm{n}$ & Body weight $(\mathrm{g})$ & Liver weight $(\mathrm{g})$ & Colon length $(\mathrm{cm})$ \\
\hline DSS + etodolac & 17 & $26.5 \pm 1.63$ & $1.18 \pm 0.06$ & $5.98 \pm 0.20$ \\
DSS & 14 & $26.1 \pm 1.13$ & $1.27 \pm 0.1$ & $6.29 \pm 0.24$ \\
Etodolac & 8 & $25.3 \pm 1.5$ & $1.11 \pm 0.05$ & $6.98 \pm 0.31$ \\
Control & 8 & $22.9 \pm 1.73$ & $1.19 \pm 0.15$ & $6.73 \pm 0.38$ \\
\hline
\end{tabular}

Values are mean $\pm \mathrm{SEM}$.

Table II. Number of neoplasias and incidences of neoplasia in the mice of each group.

\begin{tabular}{lcccccc}
\hline & & & \multicolumn{3}{c}{ No. of neoplasias } \\
\cline { 5 - 7 } Group & $\mathrm{n}$ & Incidence & Total & Category 3 & Category 4 & Category 5 \\
\hline DSS + etodolac & 17 & $14 / 17$ & 22 & 14 & 4 & 4 \\
DSS & 14 & $14 / 14$ & 42 & 29 & 0 & 3 \\
Etodolac & 8 & $0 / 8$ & 0 & 0 & 0 & 0 \\
Control & 8 & $0 / 8$ & 0 & 0 & 0 \\
\hline
\end{tabular}

gastrointestinal epithelial neoplasia (21). This classification is practical and has been recommended in order to resolve the large discrepancies that exist between Western and Japanese pathologists in the diagnosis of gastrointestinal epithelial neoplasias and as an aid to a better understanding of research data in the field of gastroenterology. This classification has five categories: category 1 , negative for neoplasia; category 2, indefinite for neoplasia; category 3 , non-invasive low-grade neoplasia; category 4, non-invasive high-grade neoplasia and category 5 , invasive neoplasia. The number of neoplasias and their macroscopical and microscopical features were recorded.

Histological assessment of the severity of colitis (ulcer score). The severity of colitis was evaluated as an ulcer score according to the modified criteria of Cooper et al (22). Ulcer scores were determined as the number of ulcers for every piece of tissue on each slide and the total score was the sum for all pieces.

Statistical analysis. The number of neoplasias in each group were expressed as mean \pm SEM and the differences between the groups were analyzed using the non-parametric MannWhitney U test. Differences at $\mathrm{p}<0.05$ were considered significant. Welch's t-test was used to compare body and liver weights, colon lengths and ulcer scores among the groups at a significance level of $\mathrm{p}<0.05$.

\section{Results}

General observations. Table I shows body and liver weights and the colon length in each group. There were no significant differences in body or liver weight, or colon length among the groups at the end of the experiment.
Number and incidence of neoplasias. The number of neoplasias and incidences of neoplasia in the mice of each group are summarized in Table II. Twenty-two neoplasias were found in the DSS + etodolac group of which 14 were low-grade neoplasia, four were high-grade neoplasia and four were carcinoma. Forty-two neoplasias were found in the DSS-alone group of which 29 were low-grade neoplasia, 10 were highgrade neoplasia and three were carcinoma. No neoplasia was observed in the etodolac-alone and control groups. The incidences of neoplasia in the mice were $82.4 \%$ in the DSS + etodolac group and $100 \%$ in the DSS-alone group.

The mean number of neoplasias per mouse $( \pm$ SEM) is presented in Fig. 2. There were 1.29 0.2 neoplasias (category 3-5) per mouse in the DSS + etodolac, 3.0 \pm 0.52 in the DSS-alone, $0 \pm 0$ in the etodolac-alone and $0 \pm 0$ in the control group. The total number of neoplasias per mouse in the DSS + etodolac group was significantly lower than that in the DSS-alone group $(\mathrm{p}<0.01)$. With regard to the grade of neoplasia, the mean $( \pm \mathrm{SEM})$ number of low-grade neoplasias (category 3) per mouse was $0.82 \pm 0.13$ in the DSS + etodolac group and $2.07 \pm 0.42$ in the DSS-alone group while the corresponding mean $( \pm$ SEM) number of high-grade neoplasias (category 4) per mouse was $0.24 \pm 0.09$ and $0.71 \pm 0.14$, respectively, and that of invasive neoplasias (category 5) per mouse was $0.24 \pm 0.09$ and $0.21 \pm 0.1$, respectively. The number of low-grade and high-grade neoplasias per mouse in the DSS + etodolac group were significantly lower than those in the DSS-alone group $(\mathrm{p}<0.05)$.

Pathological findings. Macroscopically, in the DSS + etodolac group, 20 out of the 22 neoplasias $(90.9 \%)$ were of the superficial type and $2(9.1 \%)$ were of the protruding type. In the DSS-alone group, 41 out of the 42 neoplasias $(97.6 \%)$ 


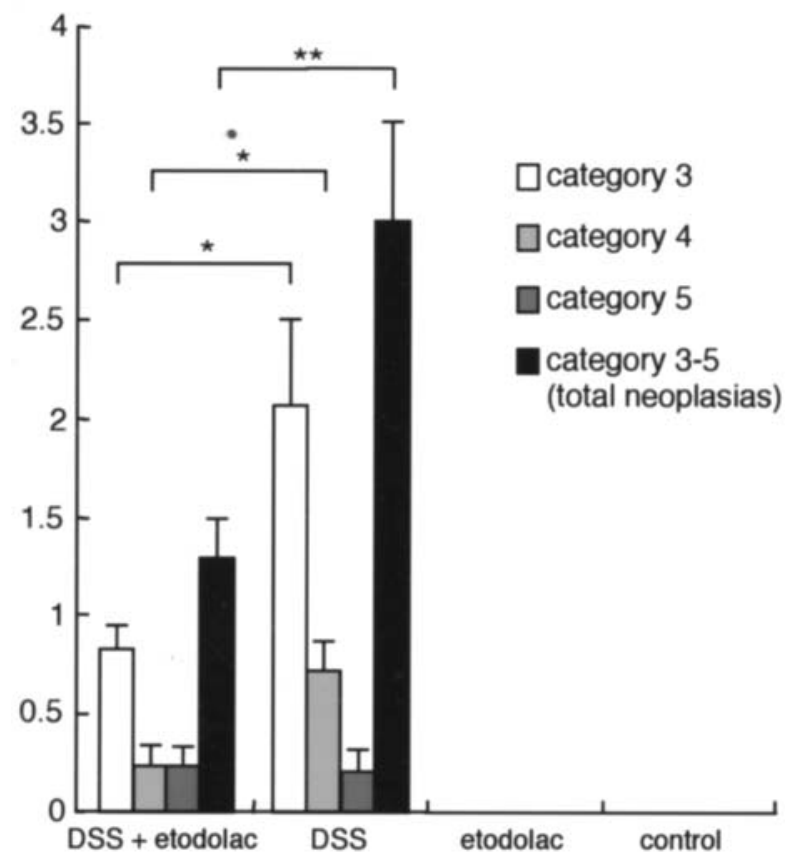

Figure 2. The mean number of neoplasias per mouse. The number of lowand high-grade neoplasias per mouse in the DSS + etodolac group was significantly lower than that in the DSS-alone group. The number of total neoplasias per mouse in the DSS + etodolac group was significantly lower than that in the DSS-alone group; ${ }^{*} \mathrm{p}<0.05,{ }^{* *} \mathrm{p}<0.01$.

were of the superficial type and $1(2.4 \%)$ was of the protruding type. In these groups, 46 out of the 61 superficial-type lesions $(75.4 \%)$ were flat lesions with the same height as the adjacent non-neoplastic epithelium (Fig. 3A). As with our study (19), most of the neoplasias that developed in this DSS colitis-associated neoplasia model using $\mathrm{p} 53^{-/-}$deficient mice were of the flat type.

Histologically, seven invasive neoplasias (category 5) were observed. Five of them were well-differentiated adenocarcinomas (Fig. 3B) and two were moderatelydifferentiated adenocarcinomas. Two of these seven neoplasias invaded the submucosal layer (Fig. 3C).

Severity of colitis (ulcer score). Table III shows the ulcer scores for all groups. With regard to acute colitis in the early phase, there was no significant difference in the ulcer score between the DSS + etodolac group and the DSS-alone group examined on day $42(8.17 \pm 1.01$ vs. $11.2 \pm 2.4, p=0.293)$. In the chronic late phase, the ulcer score of the DSS + etodolac group had a tendency to be lower than that in the DSS-alone group examined on day 126 (3.94 \pm 0.69 vs. $6.43 \pm 1.03$, $\mathrm{p}=0.086$ ). No ulcer was observed in either the etodolac-alone or control groups.

\section{Discussion}

The present study demonstrated that colonic tumorigenesis was effectively suppressed by the COX-2 inhibitor, etodolac, in $553^{-/-}$mice with DSS colitis-associated neoplasia and that this COX-2 inhibitor did not exacerbate experimental colitis. These findings indicate that the inhibition of the COX-2
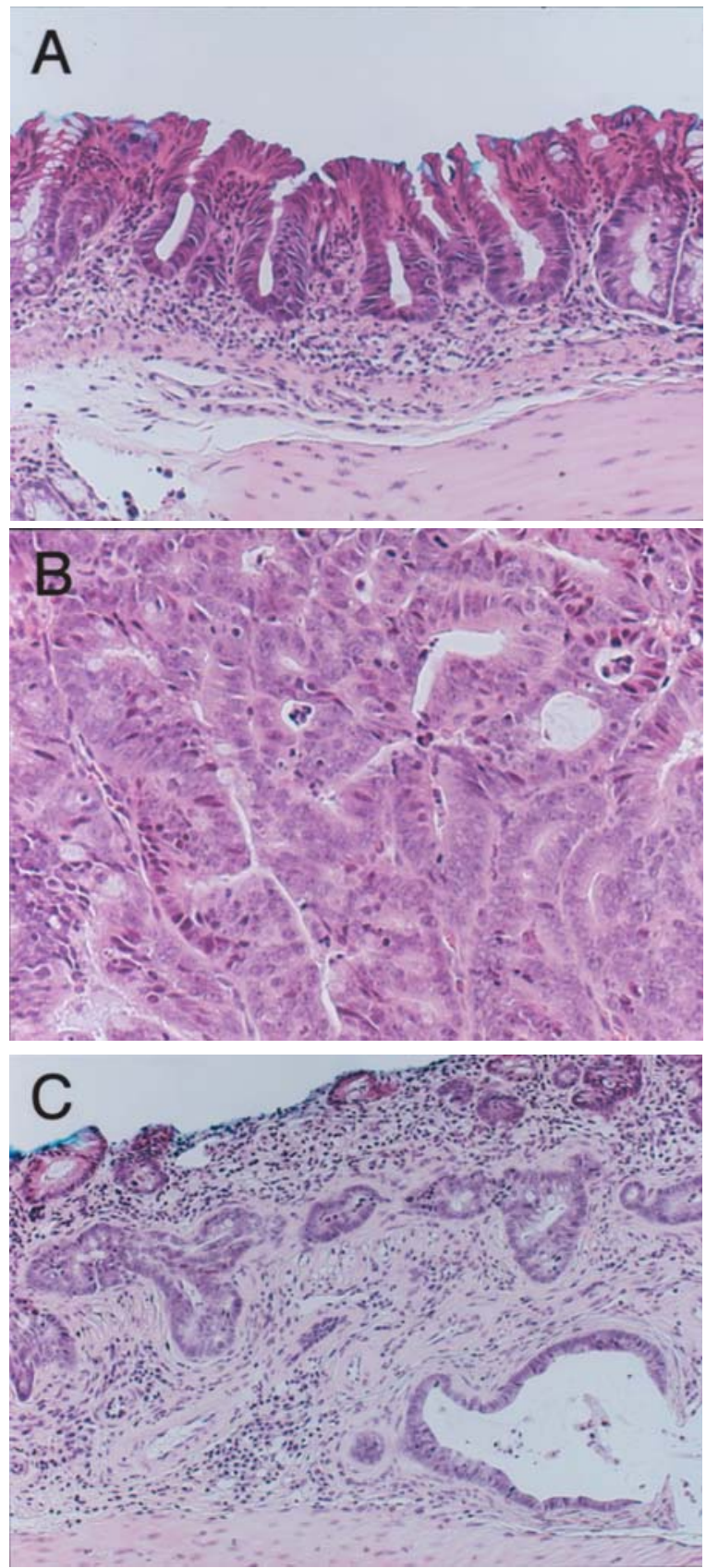

Figure 3. (A) Neoplasia in the DSS-alone group, classified as category 4 (high-grade neoplasia). This neoplasia is a flat type with the same height as the adjacent non-neoplastic epithelium. (B) Neoplasia in the DSS + etodolac group, classified as category 5 (invasive neoplasia). This neoplasia is a welldifferentiated adenocarcinoma histologically. (C) Neoplasia in the DSSalone group, classified as category 5 . This neoplasia has invaded through the muscularis mucosae into the submucosa.

activity may be a novel and safe approach for the suppression of colitis-associated tumorigenesis and that the COX-2 inhibitor would have potential as a chemopreventive agent against colitis-associated neoplasia.

COX-2 is one of the key regulatory molecules in tumor development (23-25). It supports tumor angiogenesis, inhibits tumor cell apoptosis, promotes metastatic potential and is associated with the prognosis of cancer patients $(24,25)$. Therefore, the COX-2 expression has been investigated in various kinds of tumors. In colorectal neoplasia, many reports confirmed the COX-2 expression in 
Table III. Ulcer scores in the mice of each group.

\begin{tabular}{lcccc}
\hline Group & Proximal & Middle & Distal & Total \\
\hline DSS + etodolac $\left(126\right.$ days $^{\mathrm{a}}$ & $0.71 \pm 0.16$ & $0.47 \pm 0.17$ & $2.76 \pm 0.51$ & $3.94 \pm 0.69$ \\
DSS $\left(126\right.$ days) $^{\mathrm{a}}$ & $0.86 \pm 0.22$ & $0.86 \pm 0.41$ & $4.71 \pm 0.7$ & $6.43 \pm 1.03$ \\
DSS + etodolac $\left(42\right.$ days $^{\mathrm{b}}$ & $0.5 \pm 0.29$ & $2.5 \pm 0.72$ & $5.17 \pm 0.7$ & $8.17 \pm 1.01$ \\
DSS $(42$ days) & $1.4 \pm 0.82$ & $3.4 \pm 0.53$ & $6.4 \pm 0.87$ & $11.2 \pm 2.4$ \\
Etodolac $(126$ days $)$ & $0.0 \pm 0.0$ & $0.0 \pm 0.0$ & $0.0 \pm 0.0$ & $0.0 \pm 0.0$ \\
Control $(126$ days $)$ & $0.0 \pm 0.0$ & $0.0 \pm 0.0$ & $0.0 \pm 0.0$ & $0.0 \pm 0.0$ \\
\hline
\end{tabular}

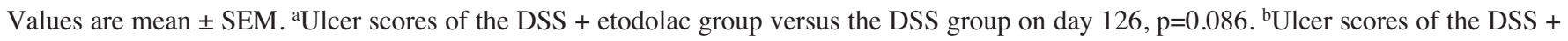
etodolac group versus the DSS group on day $42, \mathrm{p}=0.293$.

tumor tissues and demonstrated the association between the COX-2 expression level and tumor size (26-29) and that NSAIDs and COX-2 inhibitors substantially decrease the risk of sporadic colorectal neoplasia and the development of adenoma in patients with familial adenomatous polyposis $(11,12,30,31)$. Experimentally, these agents have been shown to effectively prevent colorectal neoplasia induced by carcinogenic agents such as azoxymethane (AOM) or 1,2dimethylhydrazine $(\mathrm{DMH})$ in rodents $(32,33)$ and spontaneous colorectal neoplasia in the APC min mouse model (34).

Agoff et al reported that the COX-2 expression is induced at an early stage of tumorigenesis in the UC-associated neoplasia, suggesting that the inhibition of COX-2 may be a useful chemopreventive approach (35). However, scarce data are available on the use of NSAIDs or COX-2 inhibitors for preventing UC-associated neoplasia development and progression. A case-control study by Bansal et al examined whether patients with inflammatory bowel disease (IBD) with comorbidity and requiring long-term therapy with NSAIDs had a reduced number of colorectal cancers (15). Although the difference did not reach statistical significance, patients with IBD who were also given long-term NSAID therapy to control other inflammatory diseases (e.g., rheumatoid arthritis and osteoarthritis) had a lower rate of colorectal neoplasia than those without such therapy. They also found a statistically significant protective influence against mortality in patients who were given long-term NSAID therapy compared to those without such therapy. Similarly, Eaden et al conducted a case-control study comparing 102 patients with colorectal carcinoma in UC with matched controls (16). They reported that aspirin use had a minor protective effect, although it was not statistically significant because of the small sample size. These findings may lend support to a protective role for NSAIDs in IBD-associated neoplasia, although currently the data are insufficient.

Although several experimental colitis-induced neoplasia models have been reported as candidate models of human UC-associated neoplasia, few studies exist on the protective effect of COX-2 inhibitors against colitis-associated tumorigenesis. In our previous study, we prepared a tumorigenesis rat model using trinitrobenzene sulfonic acid (TNB) and $\mathrm{DMH}$ and reported that treatment with the COX-2 inhibitor suppressed the occurrence of neoplasia in the model
(18). This result suggested that COX-2 inhibitors may serve as protective agents against UC-associated neoplasia.

However, these animal models, including the one used previously, would be inadequate as models of human UCassociated neoplasia for several reasons. In a model of colitis induced by an agent such as DSS-alone, the incidence of neoplasia is not high enough to test the effects of chemopreventive agents or analyze the molecular events participating in colitis-associated neoplasia $(22,36)$. Although the main macroscopic characteristic of UC-associated neoplasia at the early stage, dysplasia or early cancer, is a flat configuration, the neoplasia developing in colitis models has predominantly been the protruding type (22). Furthermore, the incidence of the p53-gene alteration, which is high in human UC-associated neoplasia, has been reported to be rare in animal models (22). When carcinogen is added to colitis-inducing agents, the incidence of neoplasia increases (37). However, in colonic neoplasia induced by carcinogens, several studies have shown that K-ras gene mutation, which is considered infrequent in human UC-associated neoplasia $(38,39)$, is a frequent feature $(40,41)$. Thus, the neoplasias that develop in established experimental tumorigenesis models have properties that are different from those of human UC-associated neoplasia with respect to both morphology and genetic alterations.

Therefore, in our recent study, we developed a new colitis-associated neoplasia model in p53-deficient mice using DSS and succeeded in inducing a high rate of colonic neoplasia in a background of colitis (19). In this model, most of the neoplasias that developed were flat, multiple and synchronous. In these neoplasias, K-ras mutation was not detected but the translocation of $\beta$-catenin was frequently observed. Thus, this animal model would be suitable for the study of human UC-associated neoplasia because the morphological features and molecular genetics are similar to those of human UC-associated neoplasia. In the present study, using this model, we investigated the effect of the COX-2 inhibitor, etodolac, on colitis-associated tumorigenesis. Our results showed that treatment with etodolac significantly reduced the occurrence of neoplasia, suggesting that the COX-2 inhibitor may have a chemopreventive activity in colitis-associated tumorigenesis.

With regard to the chemopreventive effect of COX-2 inhibitors on colitis-associated tumorigenesis, a critical issue 
has been whether COX-2 inhibitors are safe. A number of published reports have indicated a link between the use of NSAIDs or COX-2 inhibitors and inflammatory activity in UC (42-45). Although the use of these agents has been associated with the exacerbation of IBD in individual cases and small case series, there are still conflicting data regarding the effect of NSAIDs or COX-2 inhibitors on disease activity in patients with UC. Recently, Miedany et al conducted a double-blind, placebo-control study to assess the safety of the COX-2 inhibitor, etoricoxib and its effect on disease activity in patients with IBD (45). They indicated that etoricoxib did not cause the flare-up of IBD and that most of the patients were able to continue the drug therapy for 3 months. They also showed that there was no significant difference between the disease activity score before and after 3 months of etoricoxib therapy. They concluded that etoricoxib was safe and beneficial for most patients with IBD.

Similarly, in experimental colitis animal models, several studies investigating the influence of COX-2 inhibitors on colitis severity have yielded inconsistent results $(46,47)$. Martin et al evaluated the efficacy of the COX-2 inhibitor for the prevention of experimental colitis and demonstrated that the COX-2 inhibitor ameliorated DSS-induced colitis in mice (48). In the present study, the use of the COX-2 inhibitor, etodolac, was not associated with DSS-induced colitis severity in p53-deficient mice at the early acute phase. Furthermore, although the difference did not reach statistical significance, the ulcer score of the DSS + etodolac group had a tendency to be lower than that in the DSS-alone group at the chronic late phase. These results demonstrated that the COX-2 inhibitor ameliorates rather than exacerbates experimental colitis, suggesting that colonic tumorigenesis may be suppressed by the COX-2 inhibitor as a result of the amelioration of colitis activity in the present study. Further studies addressing the influence of COX-2 inhibitors on colitis severity in rodent models and human UC are needed to determine whether these agents are safe, or have a deleterious effect on inflammatory activity.

COX-2 inhibitors have been used clinically as antiinflammatory drugs that exert milder ulcerogenic effects in the gastrointestinal tract than classical NSAIDs. However, the long-term use of COX-2 inhibitors, especially those of the coxib family, is known to be associated with an increased risk of cardiovascular events. Motsko et al reported that the long-term use of etodolac, belonging to the pyrano acetic acid class, was not associated with a cardio-negative or cardio-protective effect in comparison with the long-term ibuprofen (49), suggesting that etodolac may be a good candidate for trials of chemoprevention against colorectal cancer. However, it would be unrealistic to give the COX-2 inhibitor to increased UC patients with long-standing and extensive colitis. Our previous study showed that individuals with estrogen-receptor gene methylation in non-neoplastic colorectal epithelium have a higher risk for the development of colorectal neoplasia among patients with long-standing and extensive UC $(50,51)$. Although further studies are needed to confirm that the COX-2 inhibitor has a chemopreventive effect on colitis-associated neoplasia, treatment with the COX-2 inhibitor for those individuals may bring on more effective management in the reduction of UC-associated neoplasia risk.

\section{Acknowledgements}

The authors thank Ms. C. Sato-Matsuyama, A. Shimizu, T. Ohtsuki, M. Katayama, S. Miyahara (Department of Surgical and Molecular Pathology, Dokkyo Medical University School of Medicine) for technical assistance. The Nippon Shinyaku Co. Ltd. gave financial support for the study.

\section{References}

1. Ekbom A, Helmick C, Zack M and Adami HO: Ulcerative colitis and colorectal cancer. A population-based study. N Engl J Med 323: 1228-1233, 1990.

2. Gyde SN, Prior P, Allan RN, et al: Colorectal cancer in ulcerative colitis: a cohort study of primary referrals from three centres. Gut 29: 206-217, 1988 .

3. Gilat T, Fireman Z, Grossman A, et al: Colorectal cancer in patients with ulcerative colitis. A population study in central Israel. Gastroenterology 94: 870-877, 1988.

4. Riddell RH, Goldman H, Ransohoff DF, et al: Dysplasia in inflammatory bowel disease: standardized classification with provisional clinical applications. Hum Pathol 14: 931-968, 1983.

5. Kornbluth A and Sachar DB: Practice Parameters Committee of the American College of Gastroenterology. Ulcerative colitis practice guidelines in adults (update): American College of Gastroenterology, Practice Parameters Committee. Am J Gastroenterol 99: 1371-1385, 2004.

6. Farrell RJ and Peppercorn MA: Ulcerative colitis. Lancet 359: 331-340, 2002.

7. Lynch DA, Lobo AJ, Sobala GM, Dixon MF and Axon AT: Failure of colonoscopic surveillance in ulcerative colitis. Gut 34: 1075-1080, 1993.

8. Choi PM, Nugent FW, Schoetz DJ Jr, Silverman ML and Haggitt RC: Colonoscopic surveillance reduces mortality from colorectal cancer in ulcerative colitis. Gastroenterology 105: 418-424, 1993.

9. Connell WR, Lennard-Jones JE, Williams CB, Talbot IC, Price $\mathrm{AB}$ and Wilkinson $\mathrm{KH}$ : Factors affecting the outcome of endoscopic surveillance for cancer in ulcerative colitis. Gastroenterology 107: 934-944, 1994.

10. Fujii S, Fujimori T, Chiba T and Terano A: Efficacy of surveillance and molecular markers for detection of ulcerative colitis-associated colorectal neoplasia. J Gastroenterol 38: 1117-1125, 2003.

11. Thun MJ, Namboodiri MM and Heath CW Jr: Aspirin use and reduced risk of fatal colon cancer. N Engl J Med 325: 1593-1596, 1991.

12. Sheehan KM, O'Connell F, O'Grady A, et al: The relationship between cyclooxygenase- 2 expression and characteristics of malignant transformation in human colorectal adenomas. Eur J Gastroenterol Hepatol 16: 619-625, 2004.

13. Reddy BS, Rao CV, Rivenson A and Kelloff G: Inhibitory effect of aspirin on azoxymethane-induced colon carcinogenesis in F344 rats. Carcinogenesis 14: 1493-1497, 1993.

14. Reddy BS, Rao CV and Seibert K: Evaluation of cyclooxygenase-2 inhibitor for potential chemopreventive properties in colon carcinogenesis. Cancer Res 56: 4566-4569, 1996.

15. Bansal P and Sonnenberg A: Risk factors of colorectal cancer in inflammatory bowel disease. Am J Gastroenterol 91: 44-48, 1996.

16. Eaden J, Abrams K, Ekbom A, Jackson E and Mayberry J: Colorectal cancer prevention in ulcerative colitis: a case-control study. Aliment Pharmacol Ther 14: 145-153, 2000.

17. Tardieu D, Jaeg JP, Deloly A, Corpet DE, Cadet J and Petit CR: The COX-2 inhibitor nimesulide suppresses superoxide and 8hydroxy-deoxyguanosine formation and stimulates apoptosis in mucosa during early colonic inflammation in rats. Carcinogenesis 21: 973-976, 2000.

18. Takeda J, Kitajima K, Fujii S, et al: Inhibitory effects of etodolac, a selective COX-2 inhibitor, on the occurrence of tumors in colitis-induced tumorigenesis model in rats. Oncol Rep 11: 981-985, 2004.

19. Fujii S, Fujimori T, Kawamata H, et al: Development of colonic neoplasia in p53-deficient mice with experimental colitis induced by dextran sulphate sodium. Gut 53: 710-716, 2004.

20. Tsukada T, Tomooka Y, Takai S, et al: Enhanced proliferative potential in culture of cells from p53-deficient mice. Oncogene 8: 3313-3322, 1993 
21. Schlemper RJ, Riddell RH, Kato Y, et al: The Vienna classification of gastrointestinal epithelial neoplasia. Gut 47: 251-255, 2000.

22. Cooper HS, Murthy S, Kido K, Yoshitake H and Flanigan A: Dysplasia and cancer in the dextran sulfate sodium mouse colitis model. Relevance to colitis-associated neoplasia in the human: a study of histopathology, B-catenin and p53 expression and the role of inflammation. Carcinogenesis 21: 757-768, 2000.

23. Oshima M, Dinchuk JE, Kargman SL, et al: Suppression of intestinal polyposis in Apc delta716 knockout mice by inhibition of cyclooxygenase-2 (COX-2). Cell 87: 803-809, 1996.

24. Tsujii M, Kawano S, Tsuji S, Sawaoka H, Hori M and DuBois RN: Cyclooxygenase regulates angiogenesis induced by colon cancer cells. Cell 93: 705-716, 1998.

25. Cao Y and Prescott SM: Many actions of cyclooxygenase- 2 in cellular dynamics and in cancer. J Cell Physiol 190: 279-286, 2002.

26. Eberhart CE, Coffey RJ, Radhika A, Giardiello FM, Ferrenbach S and DuBois RN: Up-regulation of cyclooxygenase-2 gene expression in human colorectal adenomas and adenocarcinomas. Gastroenterology 107: 1183-1188, 1994.

27. Fujita T, Matsui M, Takaku K, et al: Size- and invasiondependent increase in cyclooxygenase-2 levels in human colorectal carcinomas. Cancer Res 58: 4823-4826, 1998.

28. Fujita M, Fukui H, Kusaka T, et al: Relationship between cyclooxygenase- 2 expression and K-ras gene mutation in colorectal adenomas. J Gastroenterol Hepatol 15: 1277-1281, 2000.

29. Zhang H and Sun XF: Overexpression of cyclooxygenase-2 correlates with advanced stages of colorectal cancer. Am J Gastroenterol 97: 1037-1041, 2002.

30. Giardiello FM, Hamilton SR, Krush AJ, et al: Treatment of colonic and rectal adenomas with sulindac in familial adenomatous polyposis. N Engl J Med 328: 1313-1316, 1993.

31. Steinbach G, Lynch PM, Phillips RK, et al: The effect of celecoxib, a cyclooxygenase- 2 inhibitor, in familial adenomatous polyposis. N Engl J Med 342: 1946-1952, 2000.

32. Reddy BS, Hirose Y, Lubet R, et al: Chemoprevention of colon cancer by specific cyclooxygenase-2 inhibitor, celecoxib, administered during different stages of carcinogenesis. Cancer Res 60: 293-297, 2000.

33. Brown WA, Skinner SA, Malcontenti-Wilson C, Vogiagis D and O'Brien PE: Non-steroidal anti-inflammatory drugs with activity against either cyclooxygenase- 1 or cyclooxygenase- 2 inhibit colorectal cancer in a DMH rodent model by inducing apoptosis and inhibiting cell proliferation. Gut 48: 660-666, 2001.

34. Jacoby RF, Seibert K, Cole CE, Kelloff G and Lubet RA: The cyclooxygenase- 2 inhibitor celecoxib is a potent preventive and therapeutic agent in the min mouse model of adenomatous polyposis. Cancer Res 60: 5040-5044, 2000.

35. Agoff SN, Brentnall TA, Crispin DA, et al: The role of cyclooxygenase- 2 in ulcerative colitis-associated neoplasia. Am J Pathol 157: 737-745, 2000.

36. Okayasu I, Yamada M, Mikami T, Yoshida T, Kanno J and Ohkusa T: Dysplasia and carcinoma development in a repeated dextran sulfate sodium-induced colitis model. J Gastroenterol Hepatol 17: 1078-1083, 2002.
37. Okayasu I, Ohkusa T, Kajiura K, Kanno J and Sakamoto S Promotion of colorectal neoplasia in experimental murine ulcerative colitis. Gut 39: 87-92, 1996.

38. Fujimori T, Satonaka K, Yamamura-Idei Y, Nagasako K and Maeda S: Non-involvement of ras mutations in flat colorectal adenomas and carcinomas. Int J Cancer 57: 51-55, 1994.

39. Fujii S, Fujimori T and Chiba T: Usefulness of analysis of p53 alteration and observation of surface microstructure for diagnosis of ulcerative colitis-associated colorectal neoplasia. J Exp Clin Cancer Res 22: 107-115, 2003.

40. Jacoby RF, Llor X, Teng BB, Davidson NO and Brasitus TA: Mutations in the K-ras oncogene induced by 1,2-dimethylhydrazine in preneoplastic and neoplastic rat colonic mucosa. J Clin Invest 87: 624-630, 1991.

41. Endo T, Ookawa K, Tanaka M, Nakaji S, Tsuchida S and Sugawara K: Differences in carcinogenesis by the length of carcinogen exposure period in rat colon. Dig Dis Sci 46: 109-117, 2001.

42. Evans JM, McMahon AD, Murray FE, McDevitt DG and MacDonald TM: Non-steroidal anti-inflammatory drugs are associated with emergency admission to hospital for colitis due to inflammatory bowel disease. Gut 40: 619-622, 1997.

43. Matuk R, Crawford J, Abreu MT, Targan SR, Vasiliauskas EA and Papadakis KA: The spectrum of gastrointestinal toxicity and effect on disease activity of selective cyclooxygenase-2 inhibitors in patients with inflammatory bowel disease. Inflam Bowel Dis 10: 352-356, 2004.

44. Bonner GF, Walczak M, Kitchen L and Bayona M: Tolerance of nonsteroidal anti-inflammatory drugs in patients with inflammatory bowel disease. Am J Gastroenterol 95: 1946-1948, 2000

45. El Miedany Y, Youssef S, Ahmed I and El Gaafary M: The gastrointestinal safety and effect on disease activity of etoricoxib, a selective cox-2 inhibitor in inflammatory bowel diseases. Am J Gastroenterol 101: 311-317, 2006.

46. Kankuri E, Vaali K, Korpela R, Paakkari I, Vapaatalo H and Moilanen E: Effects of a COX-2 preferential agent nimesulide on TNBS-induced acute inflammation in the gut. Inflammation 25: 301-310, 2001.

47. Reuter BK, Asfaha S, Buret A, Sharkey KA and Wallace JL: Exacerbation of inflammation-associated colonic injury in rat through inhibition of cyclooxygenase-2. J Clin Invest 98: 2076-2085, 1996.

48. Martin AR, Villegas I and Alarcon de la Lastra C: The COX-2 inhibitor, rofecoxib, ameliorates dextran sulphate sodium induced colitis in mice. Inflamm Res 54: 145-151, 2005.

49. Motsko SP, Rascati KL, Busti AJ, et al: Temporal relationship between use of NSAIDs, including selective COX-2 inhibitors, and cardiovascular risk. Drug Saf 29: 621-632, 2006.

50. Fujii S, Tominaga K, Kitajima K, et al: Methylation of the oestrogen receptor gene in non-neoplastic epithelium as a marker of colorectal neoplasia risk in longstanding and extensive ulcerative colitis. Gut 54: 1287-1292, 2005.

51. Tominaga K, Fujii S, Mukawa K, et al: Prediction of colorectal neoplasia by quantitative methylation analysis of estrogen receptor gene in non-neoplastic epithelium from patients with ulcerative colitis. Clin Cancer Res 11: 8880-8885, 2005. 